\title{
Diffuse large B-cell lymphoma: 10 years' real-world clinical experience with rituximab plus cyclophosphamide, doxorubicin, vincristine and prednisolone
}

\author{
MATEJ HORVAT ${ }^{1}$, VESNA ZADNIK ${ }^{2}$, TANJA JUŽNIČ ŠETINA ${ }^{1}$, LUČKA BOLTEŽAR ${ }^{1}$, \\ JANA PAHOLE GOLIČNIK ${ }^{1}$, SRDJAN NOVAKOVIĆ ${ }^{3}$ and BARBARA JEZERŠEK NOVAKOVIĆ ${ }^{1}$ \\ ${ }^{1}$ Division of Medical Oncology; Departments of ${ }^{2}$ Epidemiology and ${ }^{3}$ Molecular Diagnostics, \\ Institute of Oncology Ljubljana, 1000 Ljubljana, Slovenia
}

Received September 28, 2017; Accepted December 19, 2017

DOI: $10.3892 / \mathrm{ol} .2018 .7774$

\begin{abstract}
Treatment with rituximab plus a regimen of cyclophosphamide, doxorubicin, vincristine and prednisolone (CHOP) for patients with diffuse large B-cell lymphoma (DLBCL) has proven efficacy in clinical trials. The present study investigated its application in clinical practice. This single-center, retrospective database analysis included patients with DLBCL treated at the Slovenian Institute of Oncology Ljubljana between 2004 and 2013. Overall survival (OS) and progression-free survival (PFS) were assessed according to International Prognostic Index (IPI) and revised IPI (R-IPI) categories. Overall, 573 patients with DLBCL were included in the study (median follow-up, 45.3 months; range, 0.1-143.0). Patients were categorized as IPI 'low' $(n=170$; $30 \%)$, 'low-intermediate' ( $\mathrm{n}=134 ; 23 \%)$, 'high-intermediate' $(\mathrm{n}=129 ; 23 \%)$ and 'high' $(\mathrm{n}=140 ; 24 \%)$ risk. R-IPI groups were indicated with 'very good' ( $n=59 ; 10 \%)$, 'good' $(n=245 ; 43 \%)$ and 'poor' ( $\mathrm{n}=269 ; 47 \%)$ prognosis. Ten-year OS and PFS rates were 51 and $72 \%$, respectively; median OS was 124 months and median PFS was not reached. Ten-year OS rates were 80 and $87 \%$ in low-risk and 'very good' prognosis groups, respectively, and 30 and $37 \%$ in high-risk and poor prognosis patients, respectively. This analysis of patients with DLBCL indicated that many patients treated with R-CHOP and R-CHOP-like regimens in the real-world setting have excellent outcomes.
\end{abstract}

\section{Introduction}

Diffuse large B-cell lymphoma (DLBCL) is the most common subtype of non-Hodgkin lymphomas, constituting up to $40 \%$

Correspondence to: Professor Barbara Jezeršek Novaković, Division of Medical Oncology, Institute of Oncology Ljubljana, Zaloška 2, 1000 Ljubljana, Slovenia

E-mail: bjezersek@onko-i.si

Key words: diffuse large B-cell lymphoma, real-world studies, prognosis of cases globally (1). Global epidemiological data on DLBCL are limited, but the estimated incidence is 7 per 100,000 in the USA (2). In Slovenia, the annual incidence of non-Hodgkin lymphomas was 374 in 2013 (3); 36\% of these cases are believed to be DLBCL (3) Although most commonly observed in older patients, DLBCL can affect any age group, including children (4).

DLBCL is an aggressive condition and many patients have advanced disease at diagnosis (5). The prognosis of a patient with DLBCL can be predicted using their International Prognostic Index (IPI) score. The IPI score is calculated based on age, serum lactate dehydrogenase level, Eastern Cooperative Oncology Group performance score, disease stage, and the number of extranodal disease sites (6).

Treatment for patients with DLBCL generally consists of a combination of chemotherapy [cyclophosphamide, doxorubicin, vincristine and prednisolone (CHOP)] and rituximab (R-CHOP). Although many clinical trials have demonstrated the efficacy and tolerability of R-CHOP in patients with DLBCL, (7-9) less is known about the use of this regimen in the real-world setting.

Real-world studies can complement the results of clinical trials and provide additional information that can help guide physicians making treatment decisions. Clinical trial data may not be generalizable to the broad range of patients commonly encountered in the clinical setting, as they may be limited to younger patients with good baseline characteristics. Patients encountered in real-world clinical practice may be older and have comorbidities that would have excluded their participation in rigorously designed clinical trials. Consequently, real-world studies can provide a valuable insight into these less widely studied patients.

We previously described the real-world use of R-CHOP in patients with DLBCL in Slovenia (10). We now present the results of extended follow-up in an expanded patient group.

\section{Materials and methods}

This was a single-center retrospective database analysis. Records were searched for all patients with DLBCL who were treated at the Institute of Oncology Ljubljana between 2004 and 2013 for inclusion in this analysis. 
All procedures followed in this study were in accordance with the ethical standards of the responsible committee on human experimentation (institutional and national) and the Helsinki Declaration of 1975, as revised in 2000. Individual patient consent was not collected for this study as this was a retrospective database analysis and the institutional informed consent form for treatment included consent to use the patient's data, materials and/or test results for research purposes. The study was approved as such by the institutional review board of the Institute of Oncology Ljubljana.

Patient characteristics, pathohistological diagnosis, disease stage, and response to treatment were taken from patient records. Survival data were retrieved from the Cancer Registry of the Republic of Slovenia [www. slora.si]. Treatment response was evaluated according to Cheson criteria, with the exception of criteria regarding positron-emission tomography (PET) evaluation, which was not routinely used in Slovenia before January 2016 (11). Progression-free survival (PFS) and Overall survival (OS) were calculated using Kaplan-Meier survival curves. PFS, which was determined for patients receiving first-line treatment only, was defined as the time from the beginning of treatment to disease progression for patients achieving complete or partial remission; OS was defined as the time from the beginning of treatment to the time of death or the end of observation for all patients.

Patients were categorized according to IPI (6) and revised IPI (R-IPI) (12) scores. We also compared younger patients (aged $<60$ years) with good (IPI 0 or 1 ) vs. poor (IPI $\geq 2$ ) prognosis and we compared older (aged $\geq 60$ years) vs. younger (aged $<60$ years) patients. Statistically significant differences were calculated using log-rank and $\chi^{2}$ tests.

\section{Results}

Patients. Between 2004 and 2013, 624 patients with DLBCL were treated at the Institute of Oncology Ljubljana, Slovenia. The diagnosis of DLBCL was established histologically in 523 patients $(84 \%)$ and cytologically in 101 patients $(16 \%)$ Patient characteristics are summarized in Table I.

All patients received first-line chemotherapy; 607 patients (97\%) whose tumors were CD20 positive received rituximab with their chemotherapy. Chemotherapy consisted of CHOP or a CHOP-like regimen in 575 patients (92\%); a further 32 patients $(5 \%)$ received another non-anthracycline chemotherapy regimen in combination with rituximab and the remaining 17 patients $(3 \%)$ received chemotherapy alone. A total of 136 patients (22\%) received second-line therapy and 56 patients $(9 \%)$ received third-line therapy. The average number of treatment cycles was 6.7 in the first line, 3.7 in the second line, and 2.4 in the third line. Overall, 26 patients (4\%) were receiving maintenance or consolidation treatment with rituximab because of an associated follicular lymphoma component to their disease.

IPI risk category and R-IPI prognosis category were assessed in 573 patients. When categorized according to the IPI system, 170 patients (30\%) were considered 'low' risk, $134(23 \%)$ were 'low-intermediate' risk, 129 (23\%) were 'high-intermediate' risk, and 140 (24\%) were 'high' risk. According to the R-IPI prognostic system, 59 patients (10\%)
Table I. Patient clinical and demographic characteristics at the start of treatment $(n=624)$.

\begin{tabular}{|c|c|}
\hline Characteristic & Value \\
\hline \multicolumn{2}{|l|}{ Sex, n $(\%)$} \\
\hline Male & $297(48)$ \\
\hline Female & $327(52)$ \\
\hline Median age, years (range) & $67.0(19-89)$ \\
\hline$<50$ years, $\mathrm{n}(\%)$ & $77(12)$ \\
\hline$<60$ years, $\mathrm{n}(\%)$ & $208(33)$ \\
\hline$>65$ years, $\mathrm{n}(\%)$ & $338(54)$ \\
\hline$>75$ years, $\mathrm{n}(\%)$ & $167(27)$ \\
\hline \multicolumn{2}{|l|}{ ECOG performance status, n (\%) } \\
\hline 0 & $299(48)$ \\
\hline 1 & $183(29)$ \\
\hline 2 & $90(14)$ \\
\hline 3 & $33(5)$ \\
\hline 4 & $19(3)$ \\
\hline \multicolumn{2}{|l|}{ Disease stage, n (\%) } \\
\hline I & $73(12)$ \\
\hline II & $178(29)$ \\
\hline III & $111(18)$ \\
\hline IV & $245(39)$ \\
\hline Elevated LDH level, n (\%) & $311(50)$ \\
\hline Extranodal involvement, n (\%) & $113(18)$ \\
\hline Nodal and extranodal involvement, n (\%) & $326(52)$ \\
\hline Nodal involvement, n (\%) & $179(29)$ \\
\hline \multicolumn{2}{|l|}{ Treatment regimen, n (\%) } \\
\hline Rituximab + CHOP ${ }^{a}$ & $575(92)$ \\
\hline Rituximab + other chemotherapy & $32(5)$ \\
\hline Chemotherapy alone $^{c}$ & $17(3)$ \\
\hline \multicolumn{2}{|l|}{ IPI score, $\mathrm{n}(\%)^{\mathrm{d}}$} \\
\hline 0 & $63(10)$ \\
\hline 1 & $122(20)$ \\
\hline 2 & $143(23)$ \\
\hline 3 & $141(23)$ \\
\hline 4 & $108(17)$ \\
\hline 5 & $44(7)$ \\
\hline
\end{tabular}

${ }^{\mathrm{a}} \mathrm{CHOP}$ and CHOP-like regimens (R-CHOPorR-CHOP+ methotrexate, $\mathrm{n}=557$; R-ACVBP, $\mathrm{n}=10$; R-CHOEP, $\mathrm{n}=8)$. ${ }^{\mathrm{b}} \mathrm{R}-\mathrm{COEP}, \mathrm{n}=20$; $\mathrm{R}-\mathrm{CVP}, \mathrm{n}=6$; other (some other form of rituximab-chemotherapy combination), $n=6$. ${ }^{\circ} \mathrm{CHOP}$ chemotherapy without rituximab, $\mathrm{n}=13$; other chemotherapy without rituximab, $\mathrm{n}=4$. 'IPI score could not be determined in 3 patients. CHOP, cyclophosphamide, doxorubicin, vincristine, and prednisolone; ECOG, Eastern Cooperative Oncology Group; IPI, International Prognostic Index; $\mathrm{LDH}$, lactate dehydrogenase; R-ACVBP, rituximab, doxorubicin, cyclophosphamide, vincristine, bleomycin and prednisone; R-CHOEP, rituximab, cyclophosphamide, doxorubicin, vincristine, etoposide, and prednisolone; R-CHOP, rituximab, cyclophosphamide, doxorubicin, vincristine, and prednisolone; R-COEP, rituximab, cyclophosphamide, vincristine, etoposide, and prednisolone; R-CVP, rituximab, cyclophosphamide, vincristine, and prednisolone; R-IPI, revised International Prognostic Index. 
Table II. Response to treatment.

\begin{tabular}{|c|c|c|c|c|c|}
\hline \multirow[b]{2}{*}{ Group (number of patients) } & \multicolumn{5}{|c|}{ Patients, n (\%) } \\
\hline & $\mathrm{CR}$ & PR & SD & PD & Undefined \\
\hline \multicolumn{6}{|l|}{ IPI risk group } \\
\hline Low $(n=170)$ & $101(59)$ & $67(39)$ & 0 & 0 & $2(1)$ \\
\hline Low-intermediate $(\mathrm{n}=134)$ & $62(46)$ & $64(48)$ & $1(1)$ & $3(2)$ & $4(3)$ \\
\hline High-intermediate $(n=129)$ & $56(43)$ & $56(43)$ & 0 & $4(3)$ & $13(10)$ \\
\hline High $(n=140)$ & $50(36)$ & $61(44)$ & $2(1)$ & $7(5)$ & $20(14)$ \\
\hline \multicolumn{6}{|l|}{ R-IPI prognostic group } \\
\hline Very good $(n=59)$ & $36(61)$ & $23(39)$ & 0 & 0 & 0 \\
\hline Good $(n=245)$ & $127(52)$ & $108(44)$ & $1(<1)$ & $3(1)$ & $6(2)$ \\
\hline Poor $(n=269)$ & $106(39)$ & $117(43)$ & $2(1)$ & $11(4)$ & $33(12)$ \\
\hline All patients $(\mathrm{n}=573)^{\mathrm{a}}$ & $269(47)$ & $248(43)$ & $3(1)$ & $14(2)$ & $39(7)$ \\
\hline
\end{tabular}

Table III. Progression-free survival rates according to IPI and R-IPI categories.

\begin{tabular}{|c|c|c|c|c|c|c|}
\hline \multirow[b]{2}{*}{ Patient category } & \multicolumn{5}{|c|}{ Progression-free survival rate $(\%)$} & \multirow{2}{*}{$\begin{array}{l}\text { Median progression- } \\
\text { free survival (months) }\end{array}$} \\
\hline & 1-year & 2-year & 3-year & 5-year & 10-year & \\
\hline All patients & 86 & 82 & 81 & 80 & 72 & NR \\
\hline \multicolumn{7}{|l|}{ IPI risk group } \\
\hline Low & 93 & 90 & 88 & 87 & 75 & NR \\
\hline Low-intermediate & 89 & 84 & 83 & 82 & 75 & NR \\
\hline High-intermediate & 79 & 76 & 75 & 75 & 64 & NR \\
\hline High & 78 & 73 & 71 & 71 & 71 & NR \\
\hline \multicolumn{7}{|c|}{ R-IPI prognostic group } \\
\hline Very good & 95 & 95 & 95 & 95 & 84 & NR \\
\hline Good & 89 & 85 & 84 & 82 & 73 & NR \\
\hline Poor & 78 & 75 & 73 & 73 & 66 & NR \\
\hline
\end{tabular}

IPI risk groups: Low risk, IPI=0 or 1; low-intermediate risk, IPI=2; high-intermediate risk, IPI=3; high risk, IPI=4 or 5. R-IPI prognostic groups: Very good prognosis, R-IPI=0; good prognosis, R-IPI=1 or 2; poor prognosis, R-IPI=3-5. IPI, International Prognostic Index; NR, not reached; R-IPI, revised International Prognostic Index.

fell into the 'very good' prognosis group, 245 patients (43\%) into the 'good' prognosis group, and 269 patients (47\%) into the 'poor' prognosis group.

Response to treatment. The median follow-up time was 45.3 months (range, 0.1-143.0 months). The overall response rate in all patients was $90 \%$. In the IPI 'low-risk' group, 168 patients $(99 \%)$ had a complete or partial response. The overall response rates in the 'low-intermediate', 'high-intermediate', and 'high-risk' groups were 94, 87, and 79\%, respectively ( $\chi^{2}$ test; $\mathrm{P}<0.0001$ ) (Table II). In the R-IPI 'very good' prognosis group, 59 patients $(100 \%)$ had a complete or partial response (Table II). The overall response rates in the R-IPI 'good' and 'poor' prognosis groups were 96 and $83 \%$, respectively; the difference between R-IPI groups was statistically significant $(\mathrm{P}<0.0001)$.

Progression-free survival. PFS was only determined in patients undergoing first-line treatment. The median PFS was not reached in the overall population, as shown in Table III, nor in any of the subgroups analyzed. PFS according to IPI and R-IPI category is shown in Fig. 1; PFS rates are shown in Table III. Among patients classified as IPI 'low risk', 75\% were progression-free 10 years after treatment; 10-year PFS 
Table IV. Outcomes according to age and prognosis.

Survival rate $(\%)$

$\begin{array}{llllllll} & & & & & \text { Median } \\ \text { Outcome } & \text { 1-year } & \text { 2-year } & \text { 3-year } & \text { 5-year } & \text { 10-year } & \text { survival (months) }\end{array}$

Progression-free survival

$\begin{array}{lllllll}\text { Age, }<60 \text { years } & 88 & 85 & 84 & 83 & 79 & \text { NR } \\ \text { Age. } \geq 60 \text { years } & 84 & 80 & 79 & 78 & 70 & \text { NR } \\ \text { Age, }<60 \text { years, IPI 0 or } 1 & 93 & 90 & 89 & 87 & 77 & \text { NR } \\ \text { Age, }<60, \text { IPI } \geq 2 & 83 & 79 & 79 & 79 & 79 & \text { NR }\end{array}$

Overall survival

\begin{tabular}{lllllll} 
Age, $<60$ years & 93 & 85 & 81 & 81 & 76 & NR \\
Age, $\geq 60$ years & 82 & 70 & 64 & 56 & 41 & 80.1 \\
Age, $<60$ years, IPI 0 or 1 & 98 & 95 & 91 & 91 & 87 & NR \\
Age, $<60$, IPI $\geq 2$ & 87 & 76 & 71 & 71 & 67 & NR \\
\hline
\end{tabular}

IPI, International Prognostic Index; NR, not reached.
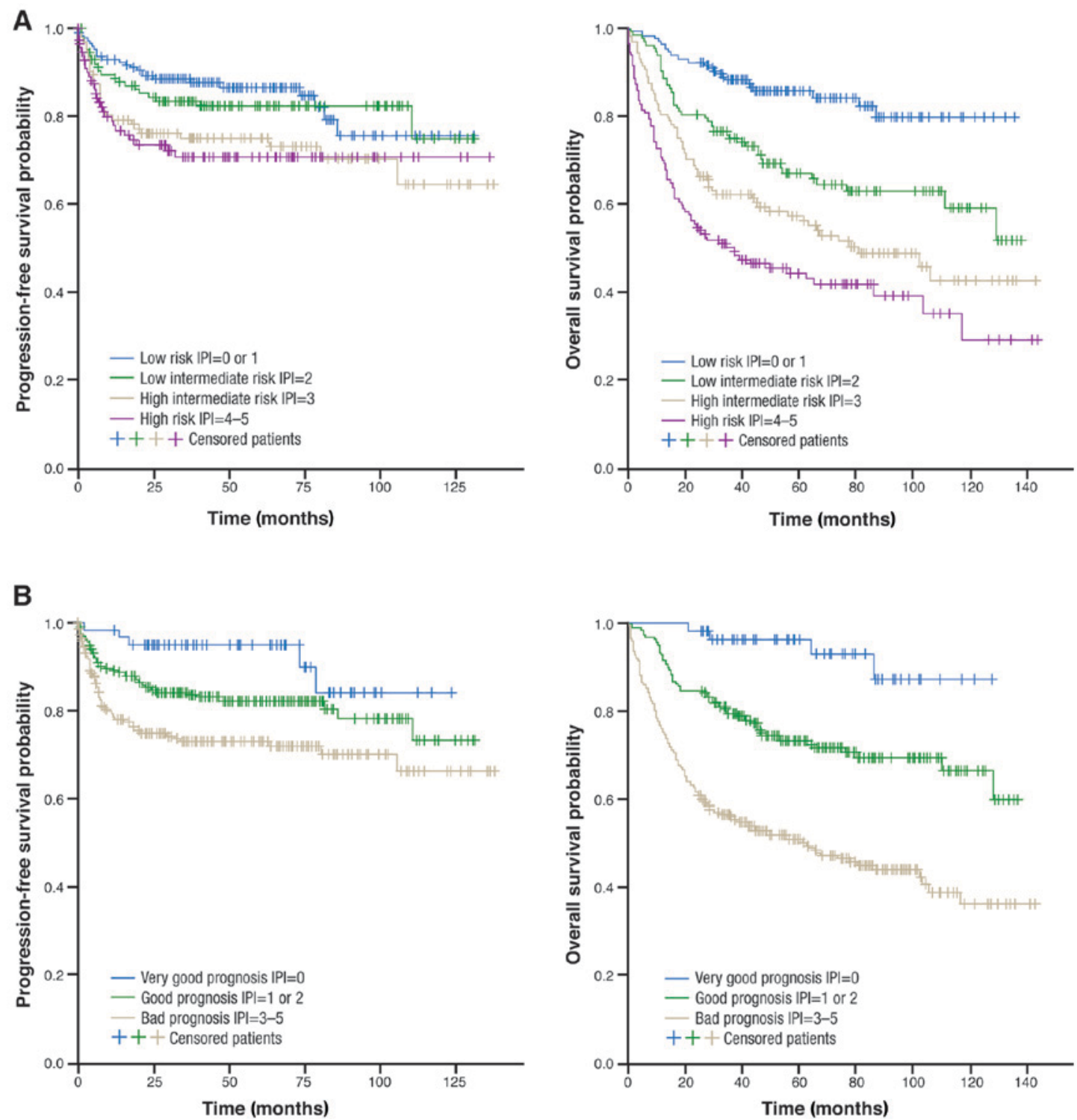

Figure 1. Progression-free and overall survival according to (A) IPI and (B) R-IPI categories. IPI, International Prognostic Index; R-IPI, revised International Prognostic Index. 
Table V. Overall survival rates according to IPI and R-IPI categories.

\begin{tabular}{|c|c|c|c|c|c|c|}
\hline \multirow[b]{2}{*}{ Patient category } & \multicolumn{5}{|c|}{ Overall survival } & \multirow{2}{*}{$\begin{array}{c}\text { Median overall } \\
\text { survival (months) }\end{array}$} \\
\hline & 1-year & 2-year & 3 -year & 5 -year & 10-year & \\
\hline All patients & 85 & 74 & 69 & 63 & 51 & 123.7 \\
\hline \multicolumn{7}{|l|}{ IPI risk group } \\
\hline Low & 97 & 92 & 88 & 86 & 80 & NR \\
\hline Low-intermediate & 90 & 81 & 75 & 67 & 60 & NR \\
\hline High-intermediate & 81 & 68 & 63 & 58 & 43 & 80.6 \\
\hline High & 71 & 56 & 50 & 45 & 30 & 35.9 \\
\hline \multicolumn{7}{|c|}{ R-IPI prognostic group } \\
\hline Very good & 100 & 98 & 96 & 96 & 87 & NR \\
\hline Good & 93 & 85 & 79 & 73 & 67 & NR \\
\hline Poor & 76 & 62 & 56 & 51 & 37 & 62.3 \\
\hline
\end{tabular}

IPI risk groups: Low risk, IPI=0 or 1; low-intermediate risk, IPI=2; high-intermediate risk, IPI=3; high risk, IPI=4 or 5. R-IPI prognostic groups: Very good prognosis, R-IPI=0; good prognosis, R-IPI=1 or 2; poor prognosis, R-IPI=3-5. IPI, International Prognostic Index; NR, not reached; R-IPI, revised International Prognostic Index.

rates in the 'low-intermediate', 'high-intermediate', and 'high-risk' groups were 75, 64, and 71\%, respectively. Among those classified as having an R-IPI 'very good' prognosis, 84\% were progression-free at 10 years after treatment; 10-year PFS rates in the good and poor prognosis groups were 73 and $66 \%$, respectively. The PFS difference between groups was statistically significant for the IPI (log-rank $\mathrm{P}=0.01)$ and R-IPI groups $(\mathrm{P}=0.001)$.

When analyzed according to age alone, no statistically significant difference was seen in PFS rates between older and younger patients. Survival outcomes were also evaluated in younger patients (aged $<60$ years) with good vs. poor prognosis (IPI 0 or 1 and IPI $\geq 2$, respectively) (Table IV and Fig. 2). PFS rates were similar in both groups of patients.

Overall survival. OS was determined in all patients undergoing treatment. The median OS was 124 months in the overall population. OS according to IPI and R-IPI category is shown in Fig. 1; OS rates are shown in Table V. Among patients classified as having an IPI 'low risk', 80\% were alive at 10 years; the 10 -year OS rates in the 'low-intermediate', 'high-intermediate', and 'high-risk' groups were 60, 43, and $30 \%$, respectively. Ten-year OS for the R-IPI 'very good prognosis' group was $87 \%$; 10 -year rates in the good and poor prognosis groups were 67 and $37 \%$, respectively. Between-group differences were statistically significant for OS for the IPI (log-rank test $\mathrm{P}<0.0001)$ and R-IPI groups (log-rank test $\mathrm{P}<0.0001$ ).

Median OS was not reached in younger patients and was 81 months in older patients. The difference in OS rates between the younger and older groups was statistically significant $(\mathrm{P}<0.0001)$. Regarding OS in younger patients (aged $<60$ years), outcomes were statistically significantly better in those with a good vs. poor prognosis (IPI 0 or 1 vs. IPI $\geq 2$, respectively) ( $\mathrm{P}=0.001$; Table IV and Fig. 2).

\section{Discussion}

Long-term follow-up data for patients with DLBCL are scarce, particularly among patients treated in the real-world setting. We have described the use of rituximab-based regimens in over 600 patients of varying ages and disease stages over a prolonged follow-up period. To the best of our knowledge, no other studies have assessed outcomes in patients with DLBCL in the real-world setting.

In our patient population, an overall 10-year PFS rate of $72 \%$ was observed, ranging from $64 \%$ in patients classed according to IPI as 'high-intermediate' risk (IPI 3) to $75 \%$ in patients with low risk (IPI 0 or 1 ) and from $66 \%$ in patients with R-IPI poor prognosis (R-IPI 3-5) to $84 \%$ in those with very good prognosis (R-IPI 0). Median PFS was not reached in any of the IPI risk categories. PFS rates were numerically but not statistically significantly higher in patients aged $<60$ years compared with those aged $\geq 60$ years, with $79 \%$ of younger patients and $70 \%$ of older patients free from progression after 10 years. Coiffier et al reported a 10-year PFS rate of $37 \%$ in their group of patients aged 60-80 years in the LNH-98.5 trial (13) lower than the 10-year rates seen in our older patients. The median PFS was 4.8 years in the LNH-98.5 trial; median PFS has not yet been reached in our group of patients after a median follow-up of 45 months. However, differences between the two patient populations and study designs call for caution when comparing the results of the two studies.

With regard to OS, we observed a 10 -year OS rate of $51 \%$ in the overall population and $41 \%$ in older patients, the latter being comparable with the $43.5 \%$ reported for patients aged $\geq 60$ years in the LNH-98.5 study (13). Purroy et al reported a 10 -year OS rate of $64 \%$ in their group of patients with DLBCL, with little difference between older and younger patients $(64 \%$ for those aged $<60$ years and $63 \%$ for those aged $\geq 60$ years) in contrast to the present study (14). They also reported a 
A

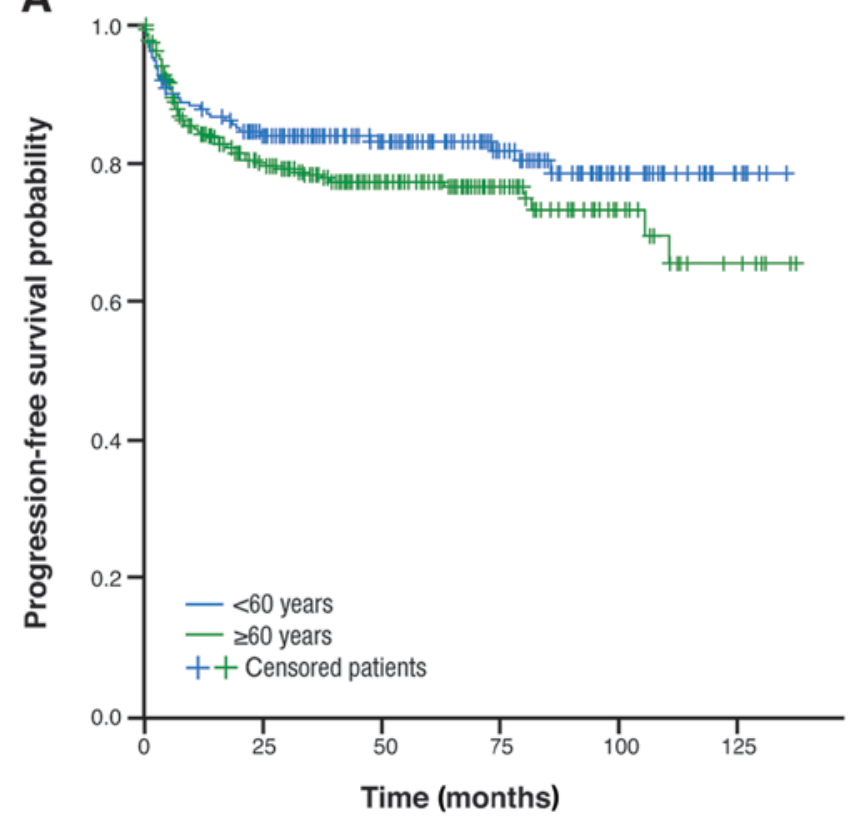

B

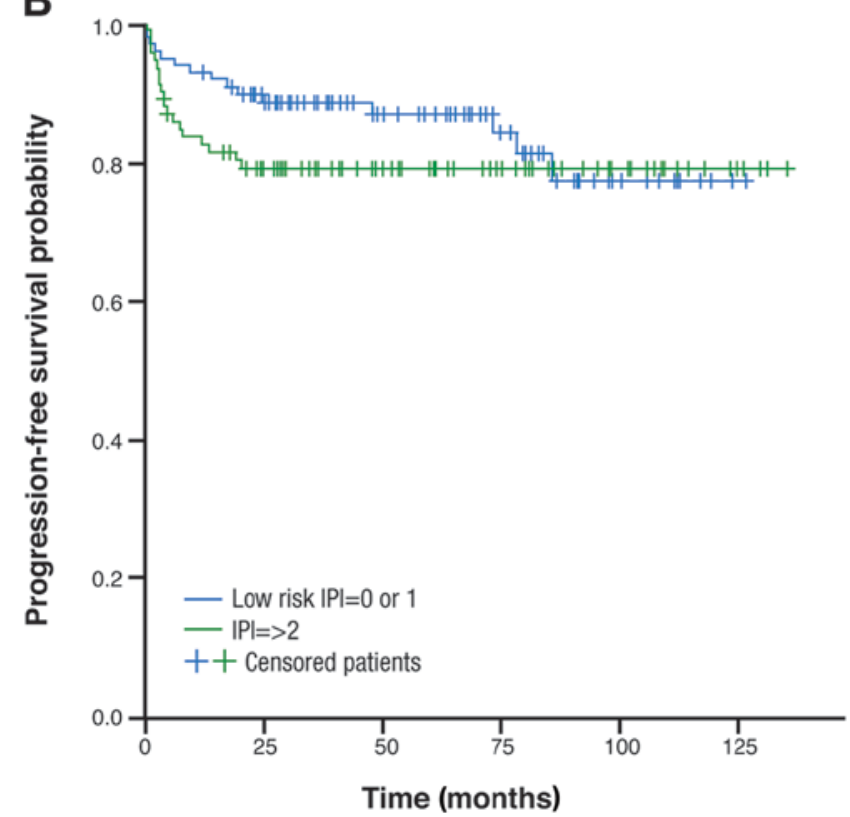

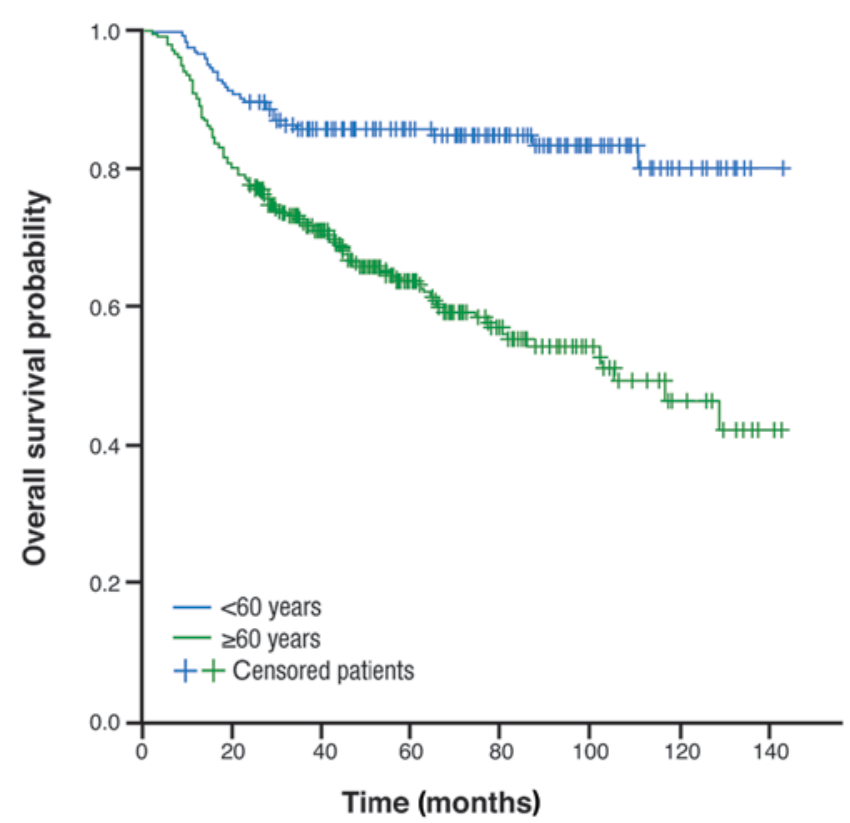

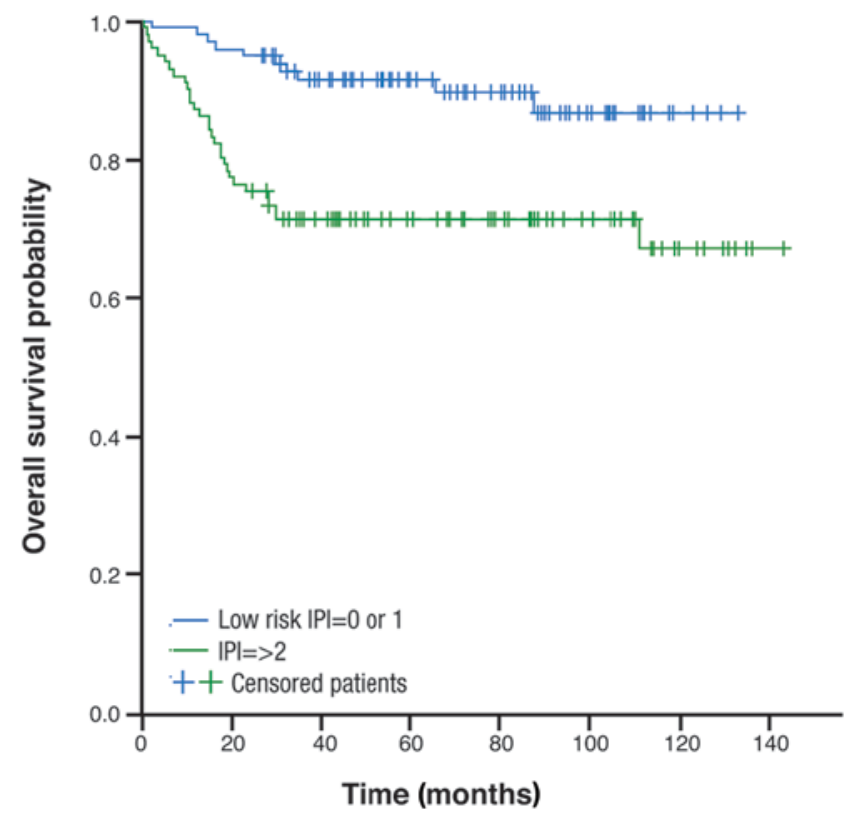

Figure 2. Progression-free and overall survival according to age and prognosis: (A) Patients aged $<60$ years and $\geq 60$ years; (B) Patients aged $<60$ years and IPI 0 or 1 and $<60$ years and IPI $\geq 2$. IPI, International Prognostic Index.

10 -year OS rate of $59 \%$ in patients with high-risk disease (IPI score $\geq 3$ ), somewhat higher than the rates we observed in our patients. Once again, however, cross-study comparisons are complicated by many factors, including differences in the treatment settings and patient populations.

We observed a statistically significant difference in OS between younger patients with good vs. poor prognosis, with 10 -year OS rates of 87 and $67 \%$, respectively. This was in line with our observations at the 5-year timepoint (10). Younger, high-risk patients clearly represent a population for whom better treatment options are needed. Intensive regimens such as R-CHOEP-14 (rituximab, cyclophosphamide, doxorubicin, vincristine, etoposide, and prednisolone) and megaCHOEP (high-dose cyclophosphamide, doxorubicin, vincristine, etoposide, and prednisolone) $(15,16)$ and R-ACVBP (rituximab, doxorubicin, vindesine, cyclophosphamide, bleomycin, and prednisolone) (17) are frequently used (18) but have not been shown to be superior to R-CHOP in this patient population (19). Consequently, European treatment guidelines currently recommend recruitment into clinical trials for young 'high-risk' and 'high-intermediate' risk patients (18). In the activated B-cell subtype of DLBCL that is more commonly seen in older patients, the addition of bortezomib, lenalidomide, or ibrutinib to standard therapy has provided encouraging indications of activity in early $(20,21)$. Results from ongoing studies such as ROBUST (NCT02285062) and PHOENIX (NCT01855750) will provide an indication as to whether this is a valid approach for this poor-prognosis group of patients. 
A plateau was observed in our PFS curves according to IPI category, with few relapses after 6 years in patients with 'low-intermediate' and 'high-risk' disease. This mirrors observations in the LNH-98.5 study (13). In contrast, an analysis of the SWOG S8736 and S0014 studies, which only included patients with limited-stage disease, revealed a pattern of late relapse in those patients (22). Patients with limited-stage disease comprised $40 \%$ of our patient population; in our group of 'low-risk' patients, some evidence of late disease progression was evident at 5-7 years post therapy, highlighting the need for continued observation of these patients.

Five-year OS rates ranged from $86 \%$ in IPI 'low-risk' patients to $45 \%$ in IPI 'high-risk' patients. Our OS rates were higher than the 5-year OS rates reported for patients in a large validation study by Olszewski et al those authors reported 5 -year OS of 74, 58, 49, and 33\% for 'low-risk', 'low-intermediate', 'high-intermediate' and 'high-risk' patients, compared with $86,67,58$, and $45 \%$, respectively, in the present study (23). Five-year OS rates in our study were higher in all three R-IPI categories compared with the validation study ('very good' prognosis: $96 \%$ vs. $87 \%$; 'good' prognosis: $73 \%$ vs. $64 \%$; 'poor' prognosis: $51 \%$ vs. $41 \%$, respectively), differences that may have been due to the characteristics of the two patient populations.

Some limitations of the present study should be considered in addition to those inherent in retrospective observational studies. PET was not used for disease staging until 2016; consequently, some patients may have been understaged at diagnosis. Since the introduction of diagnostic PET, we have observed discrete paraspinal lymphomatous masses in some patients that might have been overlooked with computed tomography. This has the potential to affect our survival data.

Although many studies have examined the efficacy of R-CHOP and similar regimens in patients with DLBCL, real-world data are scarce for these patients. We have shown that many patients treated with R-CHOP and R-CHOP-like regimens in the real-world setting can have excellent outcomes; however, accurate disease staging is essential to confidently assign prognostic scores and assess likely outcomes for patients.

\section{Acknowledgements}

The present study was supported by the Slovenian Ministry of Higher Education, Science and Technology (grant no. P3-0321). Support for third-party editorial assistance for this manuscript was provided by F. Hoffmann-La Roche, Ltd.

\section{References}

1. World Health Organization: Diffuse large B-cell lymphoma, available at http://www.who.int/selection_medicines/committees/expert/20/applications/DiffuseLargeBCellLymphoma.pdf, accessed 16 December, 2016.

2. Li Y, Wang Y, Wang Z, Yi D and Ma S: Racial differences in three major NHL subtypes: Descriptive epidemiology. Cancer Epidemiol 39: 8-13, 2015.

3. Cancer in Slovenia 2013, Ljubljana: Institute of Oncology Ljubljana, Epidemiology and Cancer Registry, available at http://www.onko-i.si/fileadmin/onko/datoteke/dokumenti/RRS/ LP 2013.pdf. Accessed 8 March, 2017.

4. Cairo MS and Perkins SL: Hematological Malignancies in Children, Adolescents and Young Adults. First edition. World Scientific Publishing Co., Singapore, 2012.
5. Sehn LH and Gascoyne RD: Diffuse large B-cell lymphoma: Optimizing outcome in the context of clinical and biologic heterogeneity. Blood 125: 22-32, 2015.

6. International Non-Hodgkin's Lymphoma Prognostic Factors Project: A predictive model for aggressive non-Hodgkin's lymphoma. N Engl J Med 329: 987-994, 1993.

7. Coiffier B,Lepage E, Brier J,Herbrecht R, Tilly H, Bouabdallah R, Morel P, Van Den Neste E, Salles G, Gaulard P, et al: CHOP chemotherapy plus rituximab compared with $\mathrm{CHOP}$ alone in elderly patients with diffuse large-B-cell lymphoma. N Engl J Med 346: 235-242, 2002

8. Habermann TM, Weller EA, Morrison VA, Gascoyne RD, Cassileth PA, Cohn JB, Dakhil SR, Woda B, Fisher RI, Peterson BA and Horning SJ: Rituximab-CHOP versus CHOP alone or with maintenance rituximab in older patients with diffuse large B-cell lymphoma. J Clin Oncol 24: 3121-3127, 2006.

9. Pfreundschuh M, Trümper L, Österborg A, Pettengell R, Trneny M, Imrie K, Ma D, Gill D, Walewski J, Zinzani PL, et al: CHOP-like chemotherapy plus rituximab versus CHOP-like chemotherapy alone in young patients with good-prognosis diffuse large-B-cell lymphoma: A randomised controlled trial by the MabThera International Trial (MInT) Group. Lancet Oncol 7: 379-391, 2006.

10. Gregoric B, Zadnik V and Jezersek Novakovic B: The diffuse large B-cell lymphoma-where do we stand now in everyday clinical practice. Radiol Oncol 46: 153-159, 2012.

11. Cheson BD, Fisher RI, Barrington SF, Cavalli F, Schwartz LH, Zucca E and Lister TA; Alliance, Australasian Leukaemia and Lymphoma Group; Eastern Cooperative Oncology Group; European Mantle Cell Lymphoma Consortium: Recommendations for initial evaluation, staging, and response assessment of Hodgkin and non-Hodgkin lymphoma: The Lugano classification. J Clin Oncol 32: 3059-3068, 2014.

12. Sehn LH, Berry B, Chhanabhai M, Fitzgerald C, Gill K, Hoskins P, Klasa R, Savage KJ, Shenkier T, Sutherland J, et al: The revised international prognostic index (R-IPI) is a better predictor of outcome than the standard IPI for patients with diffuse large B-cell lymphoma treated with R-CHOP. Blood 109: 1857-1861, 2007.

13. Coiffier B, Thieblemont C, Van Den Neste E, Lepeu G, Plantier I, Castaigne S, Lefort S, Marit G, Macro M, Sebban C, et al: Long-term outcome of patients in the LNH-98.5 trial, the first randomized study comparing rituximab-CHOP to standard CHOP chemotherapy in DLBCL patients: A study by the Groupe d'Etudes des Lymphomes de l'Adulte. Blood 116: 2040-2045, 2010.

14. Purroy N, Bergua J, Gallur L, Prieto J, Lopez LA, Sancho JM, García-Marco JA, Castellví J, Montes-Moreno S, Batlle A, et al: Long-term follow-up of dose-adjusted EPOCH plus rituximab (DA-EPOCH-R) in untreated patients with poor prognosis large B-cell lymphoma. A phase II study conducted by the Spanish PETHEMA Group. Br J Haematol 169: 188-198, 2015.

15. Holte H, Leppä S, Björkholm M, Fluge O, Jyrkkiö S, Delabie J, Sundström C, Karjalainen-Lindsberg ML, Erlanson M, Kolstad A, et al: Dose-densified chemoimmunotherapy followed by systemic central nervous system prophylaxis for younger high-risk diffuse large B-cell/follicular grade 3 lymphoma patients: Results of a phase II Nordic Lymphoma Group study. Ann Oncol 24: 1385-1392, 2013.

16. Schmitz N, Nickelsen M, Ziepert M, Haenel M, Borchmann P, Schmidt C, Viardot A, Bentz M, Peter N, Ehninger G, et al: Conventional chemotherapy (CHOEP-14) with rituximab or high-dose chemotherapy (MegaCHOEP) with rituximab for young, high-risk patients with aggressive B-cell lymphoma: An open-label, randomised, phase 3 trial (DSHNHL 2002-1). Lancet Oncol 13: 1250-1259, 2012.

17. Fitoussi O, Belhadj K, Mounier N, Parrens M, Tilly H, Salles G, Feugier P, Ferme C, Ysebaert L, Gabarre J, et al: Survival impact of rituximab combined with ACVBP and upfront consolidation autotransplantation in high-risk diffuse large B-cell lymphoma for GELA. Haematologica 96: 1136-1143, 2011.

18. Tilly H, Gomes da Silva M, Vitolo U, Jack A, Meignan M, Lopez-Guillermo A, Walewski J, André M, Johnson PW, Pfreundschuh $\mathrm{M}$, et al: Diffuse large B-cell lymphoma (DLBCL): ESMO clinical practice guidelines for diagnosis, treatment and follow-up. Ann Oncol 5 (Suppl 26): v116-v125, 2015.

19. Le Gouill S, Milpied JN, Lamy T, Delwail V, Gressin R, Guyotat D, Damaj GL, Foussard C, Cartron G, Maisonneuve H, et al: First-line rituximab (R) high-dose therapy (R-HDT) versus R-CHOP14 for young adults with diffuse large B-cell lymphoma: Preliminary results of the GOELAMS 075 prospective multicenter randomized trial. J Clin Oncol 29 (Suppl 15): S8003, 2011. 
20. Wilson WH, Young RM, Schmitz R, Yang Y,Pittaluga S, Wright G Lih CJ, Williams PM, Shaffer AL, Gerecitano J, et al: Targeting $\mathrm{B}$ cell receptor signalling with ibrutinib in diffuse large B cell lymphoma. Nat Med 21: 922-926, 2015.

21. Hong JY, Suh C and Kim WS: Evolution of frontline treatment of diffuse large B-cell lymphoma: A brief review and recent update. F1000Res 5: pii: F1000 Faculty Rev-1933, 2016.

22. Stephens DM, Li H, LeBlanc ML, Puvvada SD, Persky D, Friedberg JW and Smith SM: Continued risk of relapse independent of treatment modality in limited-stage diffuse large B-cell lymphoma: Final and long-term analysis of Southwest Oncology Group Study S8736. J Clin Oncol 34: 2997-3004, 2016.
23. Olszewski AJ, Winer ES and Castillo JJ: Validation of clinical prognostic indices for diffuse large B-cell lymphoma in the national cancer data base. Cancer Causes Control 26: 1163-1172, 2015.

(i) $\ominus$ This work is licensed under a Creative Commons Attribution-NonCommercial-NoDerivatives 4.0 International (CC BY-NC-ND 4.0) License. 